\title{
Çocuklarda ayağın radyografik değerlendirmesi
}

\author{
Radiographic evaluation of child's foot
}

\author{
Budak Akman, Melih Güven, Abdurrahman Onur Kocadal \\ Yeditepe Üniversitesi Tıp Fakültesi, Ortopedi ve Travmatoloji Anabilim Dalı, İstanbul
}

\begin{abstract}
Çocuklarda ayak bölgesi, iskelet sisteminin diğer bölgelerinde olduğu gibi gelişim süreci boyunca dinamik bir şekilde değişir ve erişkinlerden farklı bir karakteristik yapıya sahiptir. Çocuklarda ayağı oluşturan kemiklerin kemikleşme ve radyografik olarak görülme zamanları farklı olduğundan, ayağın normal gelişim sürecini bilmek yanlış tanı ve tedavilerden kaçınabilmek açısından oldukça önemlidir.

Bu derlemede, çocuklarda ayağın normal gelişim süreci ve gelişim sürecinde gözlenebilecek radyografik varyasyonlar, uygun pozisyonda çekilen ayak radyografilerinin özellikleri, ayağa ilişkin normal anatomik ilişkiler ve bunların radyografik yansımaları, ardından da sık görülen ayak deformitelerinde radyografik değerlendirmeye ait özellikler vurgulanacaktır.
\end{abstract}

Anahtar sözcükler: çocuk; pediatrik; deformite; ayak; radyografi
The child's foot changes dynamically during the development and radiological evaluation of the child's foot, and has many differences due to the fact that the child has a different characteristic structure than adult. It is very important to be aware of the normal development of the foot and to avoid misdiagnosis and treatment, since the time of ossification and radiographic appearance of the bones that form the child's foot is different.

In this review, normal development of the child's foot and radiographic differences to be followed in the developmental process, features of the foot radiographs taken in the appropriate position, and finally, features of the radiographic evaluation of common foot deformities will be emphasized.

Key words: child; pediatric; deformity; foot; radiograph
A yak, kas-iskelet sisteminde birçok biyomekanik fonksiyonu gerçekleştiren karışık bir anatomiye sahiptir. Anatomik özellikleri sayesinde; düz zeminlerde vücut ağırlığının taşınması, şok emilimi, koşma ve yürüme gibi fonksiyonlar gerçekleşirken, eğimli yüzeylere uyumsal ilişkiler de ayak ve ayak bileği aracılığıyla kusursuzlaşmaktadır. ${ }^{[1]}$

Ayak geleneksel olarak ayak arkası, ayak ortası ve ayak önü olarak üç bölümde incelenebilir. Ayak arkası talus ve kalkaneus, ayak ortası küneiformlar, naviküla ve küboid, ayak önü ise metatarslar ve falankslardan oluşur. ${ }^{[2]}$ Kemikler arası ilişkiler ve bu ilişkilerin kararlılığı ise oldukça karmaşık, ancak bir o kadar da mükemmel olan ligamentöz yapılar ile intrensek ve ekstrensik adale dengesiyle sağlanmaktadır.
Çocuklarda ayak bölgesi, iskelet sisteminin diğer bölgelerinde olduğu gibi gelişim süreci boyunca dinamik bir şekilde değişir ve erişkinlere ait anatomik özelliklerden farklı bir karakteristik yapıya sahiptir. Bu nedenle çocuk ayağının radyografik değerlendirmesi de birçok farklılık içermektedir. Çocuklarda ayağı oluşturan kemiklerin kemikleşme ve radyografik olarak görülme zamanları farklı olduğundan, ayağın normal gelişim sürecini bilmek yanlış tanı ve tedavilerden kaçınabilmek açısından oldukça önemlidir.

Bu derlemede çocuklarda ayağın normal gelişim süreci ve gelişim sürecinde gözlenebilecek radyografik varyasyonlar, uygun pozisyonda çekilen ayak radyografilerinin özellikleri, ayağa ilişkin normal anatomik ilişkiler ve bunların radyografik yansımaları, ardından da sık görülen ayak deformitelerinde radyografik değerlendirmeye ait özellikler vurgulanacaktır.

- İletişim adresi: Doç. Dr. Budak Akman, Yeditepe Üniversitesi Tıp Fakültesi, Ortopedi ve Travmatoloji Anabilim Dalı, İstanbul Tel: 0216 - 5784000 e-posta: drbudakakman@gmail.com

- Geliș tarihi: 17 Kasım $2017 \quad$ Kabul tarihi: 17 Kasım 2017 


\section{ÇOCUKLARDA AYAĞIN NORMAL GELIŞiM SÜRECI}

Ayak kemiklerini oluşturacak olan taslak kıkırdak yapıların gelişimi gebeliğin 7-9. haftalarında başlar. Kemikleşme, öncelikle metatarsların distal uçlarının gelişmesiyle ayak önünde izlenir; sonrasında da metatarslar ve falankslar oluşur. Doğum sırasında tüm metatarslar ve falankslar kemikleşmiştir. Tarsal kemikler ise gebeliğin 24-28. haftalarında oluşur ve doğum esnasında sadece talus ve kalkaneus kemikleşmiştir. Küboid doğumda bazen görülebilir, ancak 6. aya kadar kemikleşmesi normal kabul edilir. Naviküla en son kemikleşir ve genellikle 2-4 yaşlar arasında radyolojik olarak görünür hale gelir. ${ }^{[1,3]}$

Doğumla birlikte hızlı büyüme süreci devam eder ve ayak beş yaşında boyut olarak erişkin uzunluğunun yarısına ulaşır; kızlarda 12, erkeklerde ise 14 yaşında erişkin uzunluğuna ulaşmış olur. Boyutsal değişikliklerin yanı sıra, yazının ilerleyen bölümlerinde ayrıntılı olarak işlenecek olan açısal ilişkilerde de büyüme ile birlikte farklılıklar gözlenmektedir (Tablo 1). ${ }^{[4]}$

Çocuklarda ayağın radyografik değerlendirmesinde kemikleşme zamanlarının farklılığı dışında aksesuvar kemikleşme merkezlerinin ve apofizlerin varlığı da tanı aşamasında bir takım zorluklara yol açabilir. Bu nedenle, aksesuvar kemik merkezlerinin yerleşimi ve görünüm özelliklerini bilmek gereklidir. Ayaktaki bu varyasyonlar, genellikle asemptomatik olup çeşitli nedenlerle çekilen grafilerde tesadüfen saptanır.
Aksesuvar naviküla (os navikülare) en sık görülen gelişimsel varyasyondur (Şekil 1). Görülme insidansı \%4-21, çift taraflı olma olasılığı da \%50-90'dır. Aksesuvar navikülanın radyografik olarak kemikleşmesi 7-11 yaş aralığındadır. Genellikle rastlantısal olarak tanı koyulur. Nadiren semptomatik olarak ağrı meydana getirebilir. ${ }^{[5]}$ Grafilerde asimetrik ve düzleşmiş bir kemik görüntüsüne yol açarak avasküler nekroz (Köhler hastalığı) tanısı ile karışabileceğini de unutmamak gerekir. ${ }^{[6]}$

Küboid ve küneiformların bipartit veya çoklu kemikleşme merkezlerine sahip olabilecekleri bildirilmiştir. Ancak, bunlar genellikle asemptomatiktir. Ayrıca, talus ve kalkaneusta da çift kemikleşme merkezi görülebileceği, bu durumun özellikle Trizomi 21 ve Larsen sendromu ile ilişki olabileceği bildirilmiştir. ${ }^{[2]}$

Ayak arkasında talus posteriorunda gözlenebilen os trigonum, diğer bir aksesuvar kemikleşme merkezi olarak karşımıza çıkabilir (Şekil 2). Os trigonumun kemikleşmesi beş yaş civarında gözlenir ve genellikle 20 yaşında talus ile birleşmesi tamamlanır. Eğer kemikleşme süreci tamamlanmayıp ayrı bir kemik parça halinde varlığını sürdürürse, özellikle sporcular ve dansçılarda, plantar fleksiyonda ayak arkası sıkışmasına (posterior impingement) ve ağrıya yol açabilir. ${ }^{[6,7]}$

Erken çocukluk döneminde apofizi radyografik olarak gözlenmediği için kalkaneusun arka yüzeyi yumuşak, düzensiz ve testere dişi şeklinde görülür. Kalkaneus apofizi birçok merkezden kemikleşir.

Tablo 1. Ayak radyografilerinde açısal değerlendirmeler ve bunların yaşlara göre değişimleri[ ${ }^{4]}$

\begin{tabular}{|c|c|c|c|c|c|}
\hline Açı & Yenidoğan & 2 yaş & 4 yaş & 6 yaş & 9 yaş \\
\hline \multicolumn{6}{|l|}{ Ön-arka grafi } \\
\hline Talokalkaneal & $\begin{array}{c}42^{\circ} \\
\left(27^{\circ}-56^{\circ}\right)\end{array}$ & $\begin{array}{c}40^{\circ} \\
\left(27^{\circ}-50^{\circ}\right)\end{array}$ & $\begin{array}{c}34^{\circ} \\
\left(24^{\circ}-45^{\circ}\right)\end{array}$ & $\begin{array}{c}30^{\circ} \\
\left(20^{\circ}-40^{\circ}\right)\end{array}$ & $\begin{array}{c}18^{\circ} \\
\left(5^{\circ}-35^{\circ}\right)\end{array}$ \\
\hline Kalkaneus-5. metatars & $\begin{array}{c}3^{\circ} \\
\left(-9^{\circ}-14^{\circ}\right)\end{array}$ & $\begin{array}{c}0^{\circ} \\
\left(-10^{\circ}-10^{\circ}\right)\end{array}$ & $\begin{array}{c}-1^{\circ} \\
\left(-10^{\circ}-8^{\circ}\right)\end{array}$ & $\begin{array}{c}0^{\circ} \\
\left(-10^{\circ}-8^{\circ}\right)\end{array}$ & $\begin{array}{c}3^{\circ} \\
\left(-8^{\circ}-15^{\circ}\right)\end{array}$ \\
\hline Talus-1. metatars & $\begin{array}{c}20^{\circ} \\
\left(12^{\circ}-31^{\circ}\right)\end{array}$ & $\begin{array}{c}15^{\circ} \\
\left(2^{\circ}-27^{\circ}\right)\end{array}$ & $\begin{array}{c}10^{\circ} \\
\left(-4^{\circ}-23^{\circ}\right)\end{array}$ & $\begin{array}{c}7^{\circ} \\
\left(-7^{\circ}-20^{\circ}\right)\end{array}$ & $\begin{array}{c}4^{\circ} \\
\left(-9^{\circ}-17^{\circ}\right)\end{array}$ \\
\hline \multicolumn{6}{|l|}{ Yan grafi } \\
\hline Talokalkaneal & $\begin{array}{c}39^{\circ} \\
\left(23^{\circ}-55^{\circ}\right)\end{array}$ & $\begin{array}{c}41^{\circ} \\
\left(27^{\circ}-56^{\circ}\right)\end{array}$ & $\begin{array}{c}44^{\circ} \\
\left(31^{\circ}-57^{\circ}\right)\end{array}$ & $\begin{array}{c}44^{\circ} \\
\left(33^{\circ}-56^{\circ}\right)\end{array}$ & $\begin{array}{c}40^{\circ} \\
\left(28^{\circ}-52^{\circ}\right)\end{array}$ \\
\hline Tibiokalkaneal & $\begin{array}{c}77^{\circ} \\
\left(60^{\circ}-95^{\circ}\right)\end{array}$ & $\begin{array}{c}72^{\circ} \\
\left(57^{\circ}-87^{\circ}\right)\end{array}$ & $\begin{array}{c}68^{\circ} \\
\left(56^{\circ}-81^{\circ}\right)\end{array}$ & $\begin{array}{c}67^{\circ} \\
\left(58^{\circ}-76^{\circ}\right)\end{array}$ & $\begin{array}{c}68^{\circ} \\
\left(63^{\circ}-74^{\circ}\right)\end{array}$ \\
\hline Tibiotalar & $\begin{array}{c}115^{\circ} \\
\left(86^{\circ}-145^{\circ}\right)\end{array}$ & $\begin{array}{c}114^{\circ} \\
\left(95^{\circ}-130^{\circ}\right)\end{array}$ & $\begin{array}{c}113^{\circ} \\
\left(100^{\circ}-122^{\circ}\right)\end{array}$ & $\begin{array}{c}111^{\circ} \\
\left(101^{\circ}-118^{\circ}\right)\end{array}$ & $\begin{array}{c}108^{\circ} \\
\left(89^{\circ}-123^{\circ}\right)\end{array}$ \\
\hline Talus-1. metatars (Meary açısı) & $\begin{array}{c}18^{\circ} \\
\left(-2^{\circ}-44^{\circ}\right)\end{array}$ & $\begin{array}{c}12^{\circ} \\
\left(-4^{\circ}-28^{\circ}\right)\end{array}$ & $\begin{array}{c}8^{\circ} \\
\left(-5^{\circ}-22^{\circ}\right)\end{array}$ & $\begin{array}{c}7^{\circ} \\
\left(-5^{\circ}-18^{\circ}\right)\end{array}$ & $\begin{array}{c}7^{\circ} \\
\left(-7^{\circ}-20^{\circ}\right)\end{array}$ \\
\hline Talo-horizontal & $\begin{array}{c}34^{\circ} \\
\left(14^{\circ}-55^{\circ}\right)\end{array}$ & $\begin{array}{c}32^{\circ} \\
\left(18^{\circ}-45^{\circ}\right)\end{array}$ & $\begin{array}{c}30^{\circ} \\
\left(20^{\circ}-40^{\circ}\right)\end{array}$ & $\begin{array}{c}26^{\circ} \\
\left(20^{\circ}-36^{\circ}\right)\end{array}$ & $\begin{array}{c}25^{\circ} \\
\left(13^{\circ}-35^{\circ}\right)\end{array}$ \\
\hline
\end{tabular}




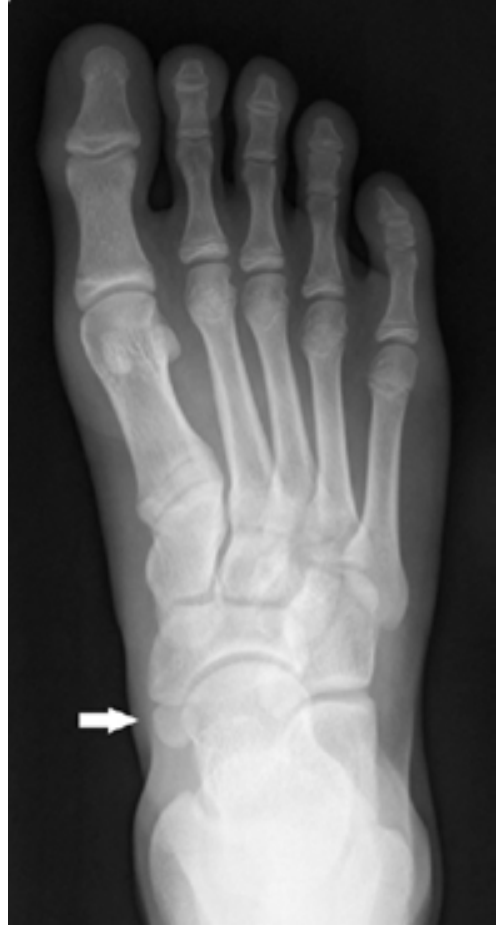

Şekil 1. 14 yaşındaki bir olguda os navikülare (beyaz ok) görünümü.

Kızlarda 4-7 yaş, erkeklerde ise 7-10 yaş aralığında hızlı büyüme döneminde ağrılı bir klinikle kendini belli edebilir. Radyografide kalkaneusa göre daha sklerotik görülür ve bazı bölgelerinde apofizi tam kat geçen radyolusen çizgilenmeler görülebilir (Şekil 3); 12-15 yaş aralığında kalkaneusun posterioru ile birleşir ve aynı dansiteye kavuşur. ${ }^{[2,8]}$

Beşinci metatarsın bazisinde yer alan apofiz her zaman metatarsın dış korteksine paralel konumdadır. Bu görünüm 5. metatars bazis kırığı ile karışabilir. Bu durumda, kırık hattının genellikle transvers ya da oblik dizilimli olduğunu unutmamak gerekir. Ayrıca, apofizyel ayrışma tanısında da dikkatli olmak gerekir. İki ayağın karşılaştırmalı grafileri ayrışma varlığında tanıya yardımcıdır. ${ }^{[2,6]}$

Normalde 1. metatarsta proksimalde, diğer metatarslarda distalde, falankslarda ise proksimalde yerleşmiş olan epifiz hatları; nadiren metatarsların bazisinde ve falanksların distallerinde yer alarak yalancı epifiz hatları olarak karşımıza çıkabilir. Ayrıca, toplumun yarısında beşinci parmakta distal interfalangeal eklemin birleşmesinden dolayı iki falanks görünümü söz konusu olabilir. Birinci parmağın proksimal falanks epifizi, tamamlanmamış kemikleşmeden dolayı iki parça halinde gözlenebilir (bifid epifiz); bu durumunda epifiz kırıkları ile karıştırılabilir. ${ }^{[6]}$

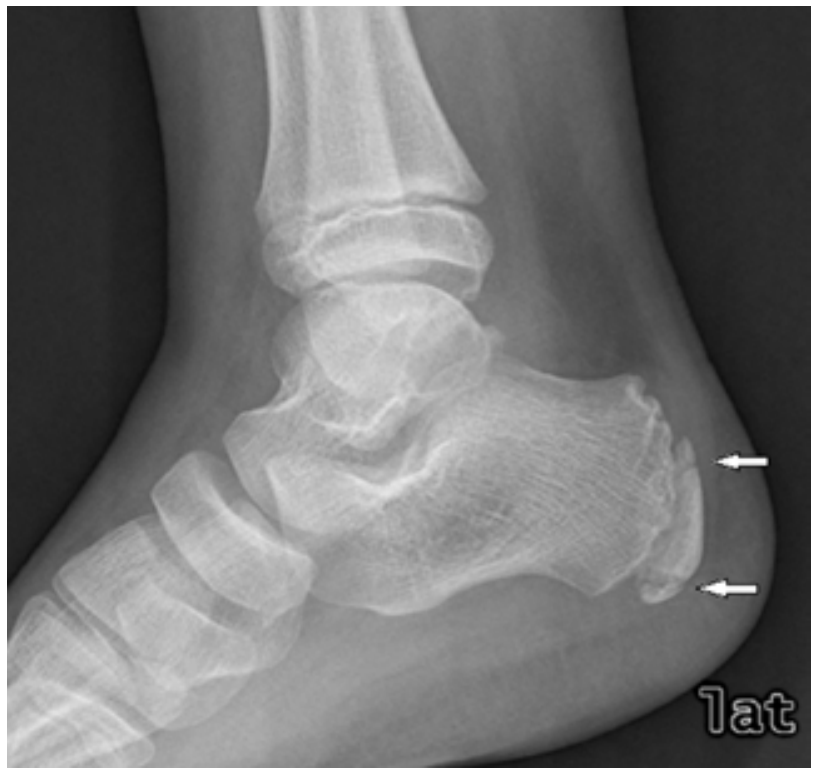

Şekil 3. 8 yaşındaki olguda kalkaneus apofizinde sklerotik görünüm ve apofizi tam kat geçen radyolusen çizgilenmeler (beyaz oklar).

\section{AYAĞIN ARKLARI VE ARKLAR ARASI NORMAL ANATOMIK ILIŞKi}

Ayak kemikleri, vücut ağırlığının taşınması, şok emici etki ve hareket sırasında salınım fonksiyonunun yerine getirilmesini sağlamak amacıyla bir takım arkları oluşturacak şekilde dizilmiştir. Ayağın normal arkları, 
tarsal ve metatarsal kemikler ile bunların arasındaki ligamantöz bağlantılar sayesinde şekillenir. Ayakta temel olarak longitudinal (mediyal-lateral) ve transvers olmak üzere iki adet ark dizilimi mevcuttur.

\section{Longitudinal Ark}

Longitudinal ark mediyal ve lateral bölümlerden oluşur. Longitudinal kemerin mediyal kısmı lateral kısımdan daha yüksektir. Kalkaneusun arka kısmı her iki longitudinal ark için posteriorda ortak yapı işlevi görür. Mediyal ark, ayak arkasında kalkaneus, sustentakulum tali ve talus başı hizasından başlar; ayak ortasında navikula ve mediyal üç küneiform kemiği geçerek ayak önünde mediyal taraftaki üç metatarsı içine alacak şekilde sonlanır. Lateral ark ise kalkaneus ile başlar; küboid ve iki lateral metatars boyunca uzanarak ayak önünde sonlanır. Vücut ağırlığı talustan talokalkaneal eklem yoluyla lateral longitudinal arka, talonavikular eklem aracılığı ile de mediyal arka aktarılır. ${ }^{[2,4,9]}$

\section{Transvers Ark}

Transvers ark, ayak ortasında tarsometatarsal eklem hizasında mediyal-lateral yönelimde yerleşmiştir. Küboid, üç küneiform ve metatarsal kemiklerin bazisinin oluşturduğu bu yapı, koronal planda bakıldığında konkav yüzeyi plantarda olacak şekilde Roma kemerine benzer bir yapı sergiler. Longitudinal arkın mediyal ve lateral bölümleri, transvers ark için sütun görevi görmektedir.

Göreceli olarak esneme özelliği olan bu arklar, vücut ağırlığı ile beraber kendi yapılarını kaybetmeyecek şekilde yassılaşır ve yük ortadan kalktığı zaman orjinal hallerine döner. Arklar, bu özelliği kemiksel anatominin yanı sıra etraflarında bulunan ligamentöz ve tendinöz yapılar aracılığıyla kazanmaktadır. Mediyal longitudinal arkın çökmesini önleyen en önemli yapı kalkaneonaviküler (spring) bağ, transvers arkın çökmesini önleyen en önemli yapı ise peroneus longus tendonudur. ${ }^{[2,4,9]}$

\section{STANDART RADYOGRAFILER VE RADYOGRAFI TEKNIĞi}

Çocuk ayak deformitelerinin değerlendirilmesinde temel olarak kullanılan radyografiler, basarak çekilen ön-arka ve yan grafilerdir. Ayağın yük altında görüntülenmesi oldukça önemlidir. Yüklenme uygulanmadan çekilen grafiler, bazı deformitelerde (örn; pes planus, vertikal talus) ayağın fonksiyonel durumunu tam olarak yansıtamayıp yanlış tanı koyulmasına neden olabilir. Çocuklarda basarak grafi çekimi her zaman kolay değildir. Bu nedenle, plantar basınç uygulamak için tahta veya plastik bir cisim kullanılarak simüle edilmiş ağılık taşıyan grafiler elde edilebilir.

\section{Ön-Arka Grafi}

Basarak çekilen grafide bacak hem koronal hem de sagittal planda yere dik olmalıdır. Ayrıca, topuğun kasetten kaldırılması ve ayağın inversiyon ve eversiyon pozisyonları engellenmelidir. Eğer grafi yatarak çekiliyorsa, dizler fleksiyonda olmalı ve ayak tabanı kasete temas etmelidir. X-ışını tüpü vertikal düzlem ile 15$30^{\circ}$ açı yapacak şekilde talus başı ve kalkaneusa doğru yönlendirilmeli ve üçüncü metatars bazisini ortalayacak şekilde konumlandırılmalıdır. ${ }^{[2,10,11]}$

\section{Yan Grafi}

Basarak çekilen grafide, bacak hem koronal hem de sagittal planda yere dik olmalıdır. Masada yatarak çekilen grafide ise ayakbileği laterali (distal fibula) ve ayak arkası kasete değmeli, ayakbileği nötral pozisyonda $\left(90^{\circ}\right)$ ve ayak tabanı kasete dik olacak şekilde yerleşmelidir. X-ışını kasete dik ve talus başını ortalayacak şekilde konumlandırılmalıdır.

Bu temel grafilerin dışında, bazı deformiteleri ve patolojileri ortaya koymak için $45^{\circ}$ iç-dış oblik grafi (örn; kalkaneonavikular koalisyon), Harris grafisi (örn; talokalkaneal koalisyon), ayakbileği zorlamalı plantar fleksiyon ve dorsifleksiyon grafisi (vertikal-oblik talus ayrımı) çekilebilir. ${ }^{[2,10,11]}$

\section{RADYOGRAFIK DEĞERLENDIRMEDE KULLANILAN AÇISAL PARAMETRELER}

\section{Ön-Arka Grafilerde Değerlendirilen Açısal Ölçümler}

Talokalkaneal açı (Kite açısı): Talus ve kalkaneusun ön-arka planda uzun aksları arasındaki açıdır (Şekil 4). Bu açı, ayak arkasının dizilimini gösterir. Normalde koronal planda kalkaneus talusa göre $10^{\circ}$ valgustadır. ${ }^{[2]}$ Ayak arkası varusu ile açı azalır, valgus yöneliminde ise artar. Açının normal değeri hakkında fikir birliği olmamakla birlikte, Vanderwilde'e göre ortalama değer beş yaş ve altı çocuklarda $25-56^{\circ}$ arasında değişmektedir. ${ }^{[4]}$ Yaş arttıkça açıda azalma görülür; $20^{\circ}$ 'nin altındaki değerler ayak arkasının varusunu gösterir. ${ }^{[2,4]}$

Talus-1. metatars arası açı: Talus ile birinci metatarsın ön-arka planda uzun aksları arasındaki açıdır (Şekil 4). Bu açı, ayak önünün ayak arkasına göre olan dizilimini gösterir. Normalde talusun uzun aksı ile 1. metatarsın uzun aksı aynı çizgi üzerinde olmalıdır. Vanderwilde'e göre bu açı yenidoğan dönemi ve beş yaş arasında $-4^{\circ}$ ile $+30^{\circ}$ gibi geniş bir aralıkta değişmekte, büyüme ile birlikte ise değer $0^{\circ}$ 'ye yaklaşmaktadır. ${ }^{[2,12]}$

Kalkaneus-5. metatars arası açı: Normalde ön-arka planda kalkaneusun uzun ekseni 4. metatarsın bazisini keserek 5. metatarsın uzun eksenine paralel olarak 
seyreder (Şekil 4). Talus-1. metatars arası açı ölçümünde olduğu gibi ayak arkası ile ayak önü dizilimlerinin kıyaslanmasını sağlar. Yaşlara göre açısal değişim daha az olup, $0^{\circ}$ 'ye yakın açısal değerler normal olarak tanımlanmıştır. ${ }^{[2]}$

Talo-naviküler örtünme açısı: Naviküla normalde talus başının tam karşısında durur ve içiçe geçer tarza bir eklemleşme oluşturur. Talus başının eklem yüzünün mediyal ve lateral köşelerini birleştiren çizgi ile navikülanın eklem yüzünün mediyal ve lateral köşelerini birleştiren çizgilere dikey olarak çizilen çizgiler arasındaki açı, talo-naviküler örtünme açısı olarak ifade edilir (Şekil 5). Normal değerleri $-20^{\circ}$ ile $-5^{\circ}$ arasında değişir. Bu açının $(+)$ değerleri talonaviküler mediyal subluksasyon ve ayak önü adduksiyonunu; (-) değerler ise talonaviküler lateral subluksasyonu ve ayak önü abduksiyonunu gösterir. ${ }^{[12]}$ Talonaviküler eklemin normal anatomik morfolojisi belirmeye başladıktan sonra (8-9 yaş) kullanılabilir.

\section{Yan Grafilerde Değerlendirilen Açısal Ölçümler}

Talokalkaneal açı: Talus ve kalkaneusun lateral planda uzun aksları arasındaki açıdır (Şekil 6). Bu açı, ayağın arka kısmının dizilimini gösterir ve normal değeri $35-50^{\circ}$ arasında değişir. Ayak arkasının varus diziliminde ve ekinusta açı azalırken, valgus diziliminde ve kalkaneus deformitesinde (kavus) artar. ${ }^{[2,4]}$

Talus-1. metatars arası açı (Meary açısı): Talus ve birinci metatarsın lateral planda uzun aksları arasındaki açıdır (Şekil 6). Bu açı, ayak ön kısmının ayak arka kısmına göre olan dizilimini gösterir. Normalde talusun uzun aksı ile birinci metatarsın uzun aksı aynı çizgi üzerinde olmalıdır. Normal değerler yaş ile değişir. Genel kural olarak $+8^{\circ}$ 'nin üzerindeki değerler pes cavus, $-4^{\circ}$ 'nin altındaki değerler ise pes planus deformitesi olarak yorumlanmaktadır. ${ }^{[2,12]}$

Tibiotalar açı: Tibianın lateral planda anatomik aksı ile talusun uzun aksı arasındaki açıdır (Şekil 7). Plantigrade basan bir ayakta talusun pozisyonunu gösterir. Ortalama değeri Vanderwilde'in çalışmasında $110^{\circ}$ olarak belirtilmiştir. ${ }^{[4]}$ Bu değer dorsifleksiyonda $70-100^{\circ}$, plantar fleksiyonda ise $120-180^{\circ}$ aralığında değişmektedir. Dorsifleksiyon ve plantar fleksiyonda ölçülen açılar arasındaki fark, aynı zamanda tibiotalar eklem hareket açıklığının da bir göstergesidir. Yeterli bir hareket açıklığının olması için açı farkının en az $25^{\circ}$ olması gerektiği ifade edilmektedir. ${ }^{[12]}$

Tibiokalkaneal açı: Tibianın lateral planda anatomik aksı ile kalkaneusun alt yüzeyine çizilen paralel çizgi arasında oluşan açıdır (Şekil 7). Normal değeri 55-95 arasındadır ve artan yaş ile azalır. Bu açı ayak bileğinin plantar fleksiyonu ve ekinus deformitesi ile artar, dorsifleksiyon ve kalkaneus deformitesi (kavus) ile azalır. ${ }^{[2,10]}$

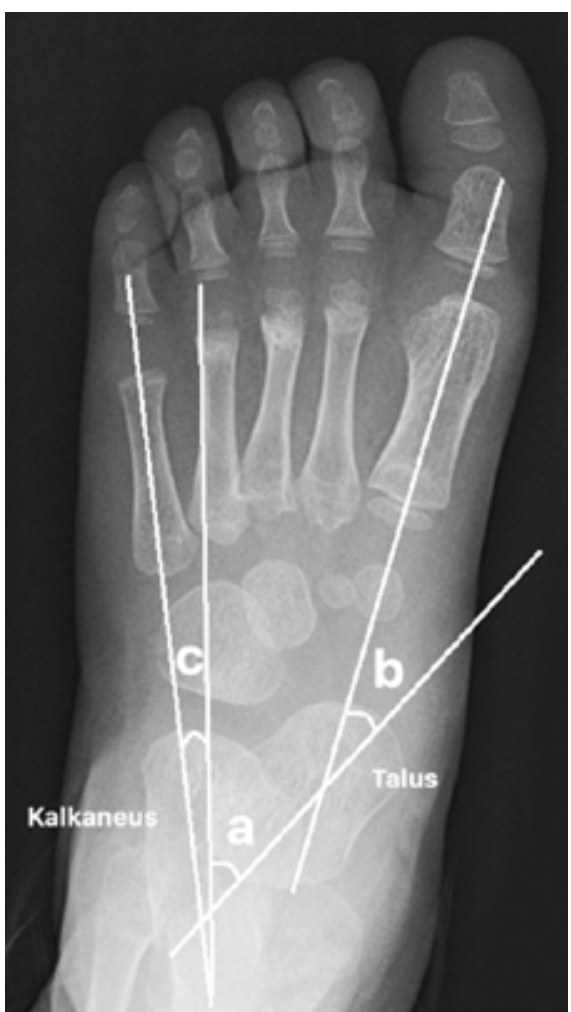

Şekil 4. Ön-arka ayak grafisinde; talokalkaneal açı (Kite açısı) [a], talus-1. metatars arası açı [b], kalkaneus-5. metatars arası açı [c].

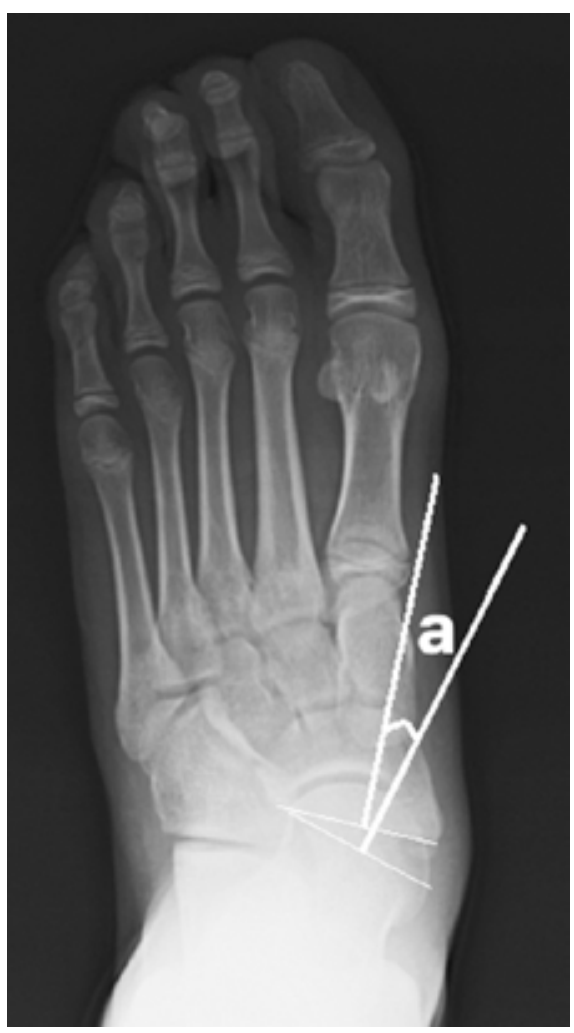

Şekil 5. Ön-arka ayak grafisinde talo-naviküler örtünme açısı [a]. 


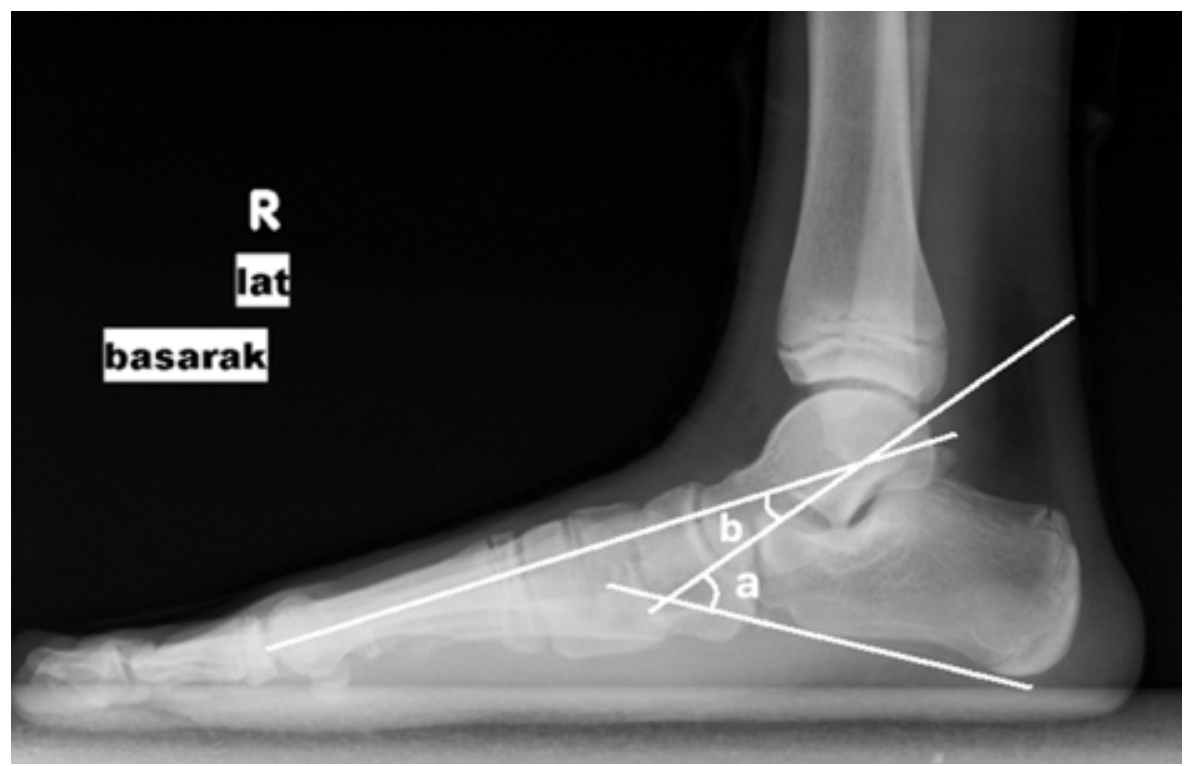

Şekil 6. Yan ayak grafisinde; talokalkaneal açı [a], talus-1. metatars arası açı (Meary açısı) [b].

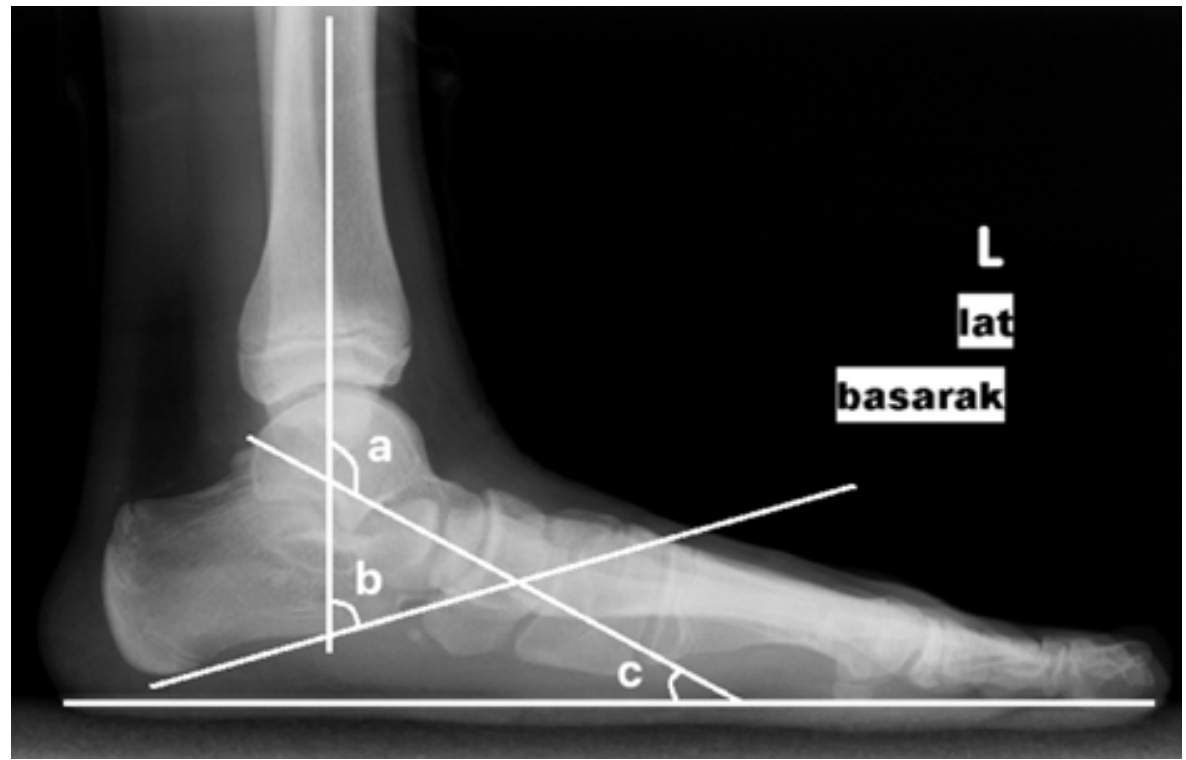

Şekil 7. Yan ayak grafisinde; tibiotalar açı [a], tibiokalkaneal açı [b], talo-horizontal açı [c].

Talo-horizontal açı: Lateral planda talusun uzun aksı ile horizontal plan (yer planı) arasındaki açıdır (Şekil 7). Bu açı talusun plantar eğimini gösterir ve oblik-vertikal talusun değerlendirilmesinde kullanılır. Doğum sonrası ortalama değeri $35^{\circ}$ olan bu açı, minimal değişiklik ile beş yaş civarında $30^{\circ}, 9-10$ yaşlarında ise $25^{\circ}$ 'ye geriler. ${ }^{[4,10]}$

Kalkaneal inklinasyon açısı: Kalkaneusun alt yüzeyine paralel çizilen çizgi ile kalkaneus en alt noktasından 5. metatars başının en alt noktasına çizilen çizgi arasındaki açıdır (Şekil 8). Kalkaneusun horizontal plandaki inklinasyonunu ifade eder; $21-29^{\circ}$ arasındaki normal değerler, ekinus deformitesinde azalmakta, kavus deformitesinde ise artmaktadır. ${ }^{[12]}$

Mediyal longitudinal ark açısı: Basarak çekilen yan grafilerde talus başının en alt noktasından 1. metatars başının en alt noktasına çizilen çizgi ile talus başının en alt noktasından kalkaneusun en alt noktasına çizilen çizgi arasındaki açıdır (Şekil 8). Ayaktaki mediyal longitudinal arkın yüksekliği hakkında fikir verir. Normal değerleri $121,5-132,5^{\circ}$ arasındadır. Planus deformitesinde artmakta, kavus deformitesinde ise azalmaktadır. ${ }^{[12]}$ 


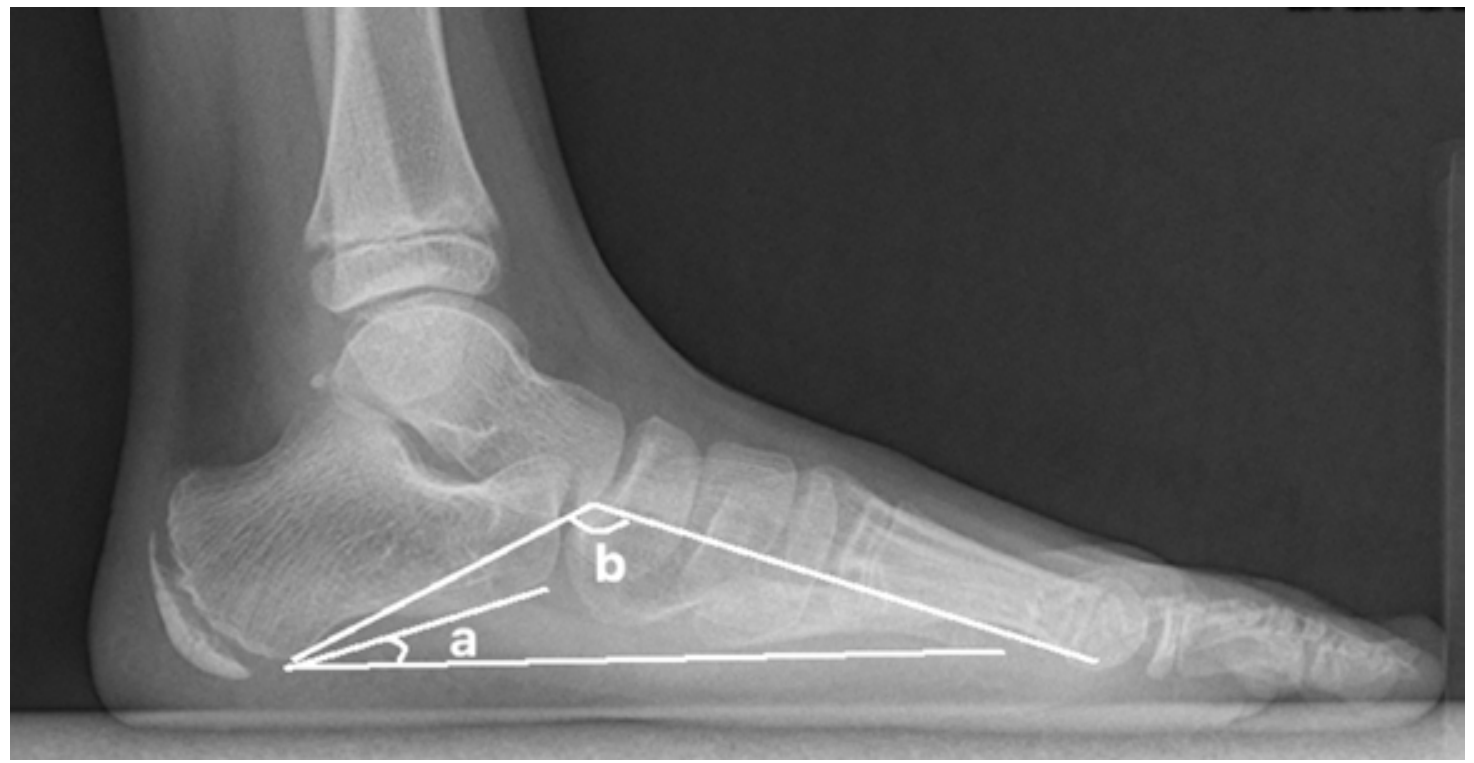

Şekil 8. Yan ayak grafisinde; kalkaneal inklinasyon açısı [a], mediyal longitudinal ark açısı [b].

\section{ÇOCUKLARDA SIK GÖRÜLEN AYAK DEFORMITELERINDE RADYOGRAFIK DEĞERLENDIRME}

\section{Metatarsus Adduktus ve Zigzag Ayak (Skew Foot)}

Metatarsus adduktus, yaygın olarak görülen konjenital bir ayak deformitesidir. Zigzag ayak ise daha nadir olarak görülür. Her iki deformite de tarsometatarsal eklemden ayak önünün supinasyonu ve mediyal subluksasyonu ile karakterizedir. Ancak, zigzag ayakta ayak önünün varusuna ek olarak, ayak arkasında valgus, ayak ortasında ise lateral subluksasyon ile daha karışık bir anatomik ilişki söz konusudur. Ayak ortasındaki bulgular, metatarsus adduktusu zigzag ayaktan ayırmaya yarar. Zigzag ayakta talus başının çevresinde navikülanın lateral subluksasyonu söz konusudur. Bu durum ayrıca, deformitedeki ayak arkası valgusunu açıklar. Özellikle erken çocukluk döneminde sınırIı sayıda kemikleşme merkezinin olması nedeniyle, bu deformiteler arasında radyolojik olarak ayırım yapmak güçleşmektedir. ${ }^{9,10]}$

Radyografiler, metatarsus adduktus tanısı koymak için her zaman gerekli değildir. Ancak, konservatif tedaviye cevap vermeyen şiddetli ve klinik olarak zorlandığımız olgularda radyografik değerlendirmeye başvurulabilir. Deformite ayak arkasına göre ayak önünün varusu olduğundan, röntgen çekiminde ayak ortası ve önü üzerine odaklanılmalıdır. Metatarsus adduktusun zigzag ayaktan ayırımını sağlayan sabit bir ayak arkası valgus deformitesinin olup olmadığını anlamak için, basarak ön-arka ve yan grafiler çekilmelidir. Ön-arka grafide; talus-1. metatars arası açı ölçümü ile ayak önü varusunun şiddeti gösterilebilir. Metatarsus adduktusta talokalkaneal açı normal sınırlardadır. Zigzag ayakta ise talokalkaneal açı artmıştır. Ayrıca, navikülanın talus başı çevresindeki lateral subluksasyonu zigzag ayak için önemli bir radyografik bulgudur. Ancak, navikülanın kemikleşmesi geç dönemde gerçekleştiği için, lateral subluksasyonu erken çocukluk döneminde göstermek her zaman mümkün olamayabilir. ${ }^{[9,10]}$

\section{Konjenital Vertikal-Oblik Talus}

Konjenital vertikal ve oblik talus, konjenital pes planus spektrumunda yer alan deformitelerdendir. Bu patolojiler, artrogripozis, nörofibromatozis, serebral palsi gibi nöromusküler hastalıklarla ilişkili olabilir. ${ }^{[7,10]}$

Vertikal talus ve oblik talus deformitelerinde basarak (en azından basmayı taklit ederek) çekilen ön-arka ve nötral pozisyonda yan grafiler dışında, zorlamalı dorsifleksiyon ve plantar fleksiyonda çekilen yan grafiler değerlendirilmelidir. Bu grafilerde talokalkaneal, tibiokalkaneal, talus-1. metatars arası, tibiotalar ve talohorizontal açılar ölçülmelidir. Her iki deformitede de; ön-arka ve yan grafilerde talokalkaneal açı ayak arkasındaki ekinovalgus deformitesinden dolayı artmıştır. Zorlamalı dorsifleksiyonda çekilen yan grafilerde ayak arkası ekinusu gözlenir ve bu durum artmış tibiokalkaneal açı ile kendisini gösterir. Ayak önünün ayak arkası ile olan ilişkisini gösteren talus-1. metatars arası açı (+) yönde artmıştır. Talus dikey yerleşimli olduğundan, 
talo-horizontal ve tibiotalar açılar sırasıyla $90^{\circ}$ ve $180^{\circ}$ 'ye yaklaşır. ${ }^{[7]}$

Vertikal ve oblik talus ayrımını yapmak, prognoz ve tedavi şekilleri açısından oldukça önemlidir. Vertikal talus, talusun vertikal yerleşimi ve rijid talonaviküler çıkık ile karakterizedir. Oblik talusta ise talonaviküler ilişki devam eder; dorsifleksiyonda dorsal subluksasyon görülürken, plantar fleksiyonda eklem redükte olmaktadır. Bu iki ayrı patolojinin ayrımını yapmak için altın standart grafi, zorlamalı plantar fleksiyonda çekilen yan grafidir. Bu grafide vertikal talus olgularında talonaviküler çıkık devam eder. Ancak, oblik talusta plantar fleksiyon grafisinde talonaviküler redüksiyonun sağlandığı ve artmış talokalkaneal açının azalma eğiliminde olduğu gözlenir. Doğum sonrası, ayak ortasında, özellikle navikülada henüz kemikleşme olmadığı için radyografik veriler oldukça sınırlıdır. Bu nedenle, talus ve 1. metatars aksları üzerinden izafi bir değerlendirme yapılabilir. Ayrıca, vertikal talusta, talusun tibianın anatomik aksına hemen hemen paralel bir şekilde konumlanması, kalkaneusun ekin pozisyonunda olması gibi karakteristik radyografik özellikler mevcuttur. ${ }^{[7,12]}$

\section{Tarsal Koalisyon}

Rijid pes planusa yol açan bir deformite olan tarsal koalisyon, iki ya da daha fazla tarsal kemiğin fibröz (sindesmozis), kartilajinöz (sinkondrozis) veya kemiksel (sinostozis) olarak füzyonunu ifade eder. Koalisyonlar, erken çocukluk döneminde daha çok fibröz ve kartilajinöz yapıda iken adolesan dönemde kemiksel yapı özelliği kazanır. Bilateral görülme olasılığı \%50 olduğu için her iki ayak radyografik olarak incelenmelidir. Füzyon $\% 90$ oranında kalkaneonaviküler ya da talokalkaneal koalisyon şeklindedir. Kemikleşme oluşmamış koalisyonlarda bir miktar subtalar hareket varken, kemikleşme olduktan sonra hareket kaybolur ve ayak ağrılı olmaya başlar. Koalisyonlarda kemikleşme zamanları farklı olup talonaviküler koalisyonlar 3-5 yaş, kalkaneonaviküler koalisyonlar 8-11 yaş, talokalkaneal koalisyonlar ise 12-16 yaş arasında kemikleşir. ${ }^{[11,12]}$

Tarsal koalisyonun ilk radyografik değerlendirmesi, ayağın ön-arka, yan ve oblik grafileri üzerinden yapılmalıdır. Koalisyonlarda temel görüntü ayak arkası valgusu ve longitudinal ark çökmesi olduğundan, hem ön-arka hem de yan grafilerde talus-1. metatars arası açı (+) yönde artmış bir değer ile karşımıza çıkar. ${ }^{[10]}$

Kalkaneonaviküler koalisyonlar en iyi $45^{\circ}$ oblik grafilerde görülür. Kalkaneus ve navikula arasındaki boşluk eğer kemikleşme olmuşsa kapanmış olarak görülür. Yan grafide kalkaneusun anterior proçesinin naviküla üzerine tübüler şekilde uzaması ile oluşan "ant eater" bulgusu kalkaneonaviküler koalisyon için karakteristiktir. ${ }^{[10,11]}$

Talokalkaneal koalisyonu ön-arka ve yan grafilerde tanımlamak daha zordur. Bunun için ayak arkasının aksiyel grafisi (Harris grafisi) tanımlanmıştır. Bu grafide sadece orta veya arka fasette yer alan koalisyonlar değerlendirilebilir. Ek olarak yan grafide, talus kubbesinin mediyal tarafı ile sustentakulum tali arasında dairesel olarak devamlılık gösteren kemiksel köprüleşme olarak tanımlanabilecek " $C$ " bulgusu talokalkaneal koalisyonda kullanışlıdır. Ancak, bu bulgunun patognomonik olmadığı ve taban çökmesi olgularının \%33'ünde görülebileceği de bildirilmektedir. Bu nedenle, tarsal koalisyon olgularında tanıyı doğrulamak amacıyla başvurulabilecek diğer görüntüleme tetkikleri bilgisayarlı tomografi ve manyetik rezonans görüntülemedir. ${ }^{[10,12,13]}$

\section{Doğuştan Çarpık Ayak (Pes Ekinovarus)}

Pes ekinovarus tanısı klinik bir tanıdır ve tanı koymak için radyografilere ihtiyaç duyulmaz. Ayrıca, deformitenin karmaşık ve çok planlı olması, naviküla başta olmak üzere tarsal kemiklerde kemikleşmenin olmamasından dolayı, erken çocukluk döneminde radyografileri yorumlamak güçtür. Doğuştan çarpık ayak deformitesinde, aşağıda sıralanmış durumlarda ise radyografik değerlendirme ortopedistler için yol gösterici olabilir ${ }^{[7,12]}$ :

1. Alçılama tedavisinde talonavikular subluksasyonun ve ayak önü adduksiyonundaki düzelmenin gözlenmesi.

2. Konservatif tedavi sırasında karşılaşılabilecek düzeltme sorunları.

3. Cerrahi sonrasında dizilimin değerlendirilmesi ve ayak gelişiminin takibi.

4. İleri yaş olgularda cerrahi tedavi planlaması.

5. Ameliyat sırasında elde edilen düzelmenin değerlendirilmesi.

Ön-arka grafide, talokalkaneal açı, talus-1. metatars arası açı ve kalkaneoküboid ilişki değerlendirilebilir. Talokalkaneal açı, ayak arkası varus-valgus dizilimini gösteren ve sık kullanılan bir açıdır. Deformitede, önarka planda talus ve kalkaneus paralel hale gelir ve üst üste görülmeye başlar. Bu durum, talokalkaneal açıda azalmaya yol açar. Yine bu planda, talusun ön kenarı ile kalkaneusun ön kenarı arasındaki diverjans miktarı (talokalkaneal diverjans) ayak arkası dizilimi için fikir verir; (-) değerler varusu gösterirken (+) değerler valgusu gösterir (Şekil 9). ${ }^{[7]}$

Navikülanın talus başına göre konumu, naviküla radyografide görünür hale geldikten sonra (2-4 yaş) 


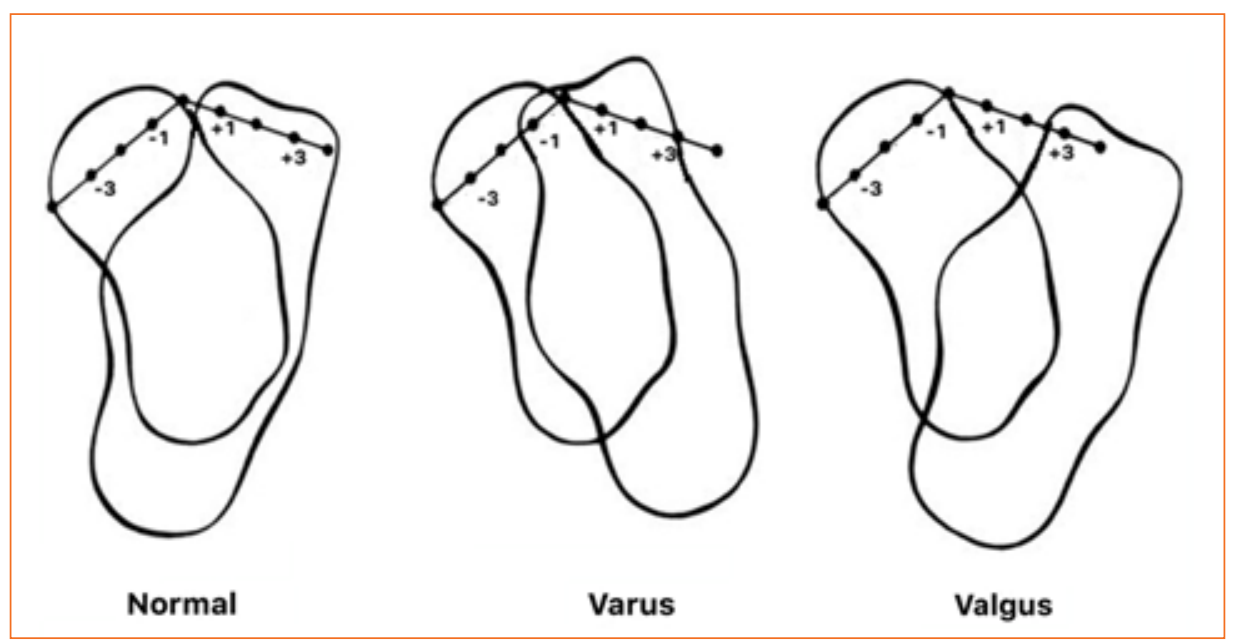

Şekil 9. Ön-arka planda talokalkaneal diverjans.

belirlenebilir. Normal ilişkide navikülanın merkezi talus başının distal ucunun merkezinde bulunur. Doğuştan çarpık ayakta bu ilişki bozulur ve naviküla mediyale deplase olur. Navikülanın kemikleşmesinden önce ise bu ilişki talar aks ile belirlenir. Normalde talus başının ortasından çizilen çizgi 1. metatars bazisinden geçmelidir. Doğuştan çarpık ayakta ise aks 1 . metatars bazisinin lateralinden geçer. Ayrıca talus-1. metatars arası açı ayak önü adduksiyonuna bağlı olarak (+) yönde artmıştır. Bu açıdaki artma ya da azalma, deformitenin şiddeti ile doğru orantılıdır. Küboid de deformitenin şiddeti ile doğru orantılı olarak içe kaymıştır. ${ }^{[2,7,12]}$

Yan grafide ise talokalkaneal açı, tibiokalkaneal açı ve talus-1. metatars arası açı değerlendirilebilir. Hem talokalkaneal hem de tibiokalkaneal açı ölçümleri ayak arkası ekinusu hakkında bilgi verir. Tibiokalkaneal ölçüm daha kesin bir değerlendirme yapma imkanı sunarken, pratikte sıklıkla talokalkaneal açı ölçümü kullanılır. Talokalkaneal açı azalmış ve talus ile kalkaneusun uzun eksenleri hemen hemen paralel hale gelmiştir. Kalkaneus, talusun uzun aksına göre plantar fleksiyon pozisyonundadır. Tibiokalkaneal açı, ayak arkası ekinus derecesi ile doğru orantılı olarak artmıştır. Ancak, tibiokalkaneal açı değerlendirmesinde yan grafinin zorlamalı dorsifleksiyonda çekilmesine dikkat edilmelidir. ${ }^{7,12]}$

Navikülanın talus ile olan uyumuna bakıldığında ise; navikülanın vertikal yüksekliğinin 1/3'ünden daha fazla olan dorsal subluksasyon patoloji için anlamlı kabul edilir. Eğer naviküla kemikleşmemiş ise talar aks ile 1. metatars bazisi arasındaki ilişkiye bakılmalıdır. Talus-1. metatars arası açı (Meary açısı) bu amaçla kullanılır. Bu ayrıca, doğuştan çarpık ayak deformitesinde "rocker-bottom" olarak adlandırılan taban çökmesi deformitesinin değerlendirilmesini sağlar. Normalde talus uzun aksı ile 1. metatars aksının aynı düzlemde olması gerekir. Deformitede bu açı volar tarafta oluşmaktadır. ${ }^{[7]}$

Doğuştan çarpık ayak deformitesinde ayak bileği hareket genişliğini doğru bir şekilde analiz etmek için tibiotalar açı ölçümü yapılabilir. Bu açı, zorlamalı dorsifleksiyon ve plantar fleksiyonda ölçülen açılar arasındaki fark ile hesaplanır ve ayak bileği hareket genişliğini ifade eder. ${ }^{[7]}$

\section{Düztabanlık (Pes Planus)}

Düztabanlık tanısı için genellikle radyografik değerlendirmeye ihtiyaç yoktur. Ancak, rijid bir deformiteyi değerlendirmek ve cerrahi planı yapmak için radyografiler kullanılır. Esnek düztabanlık için ön-arka ve yan grafiler yeterliyken, sert düztabanlıkta, tarsal koalisyon ayrımı yapabilmek amacıyla, oblik ve ayak arkası aksiyel görüntüsünün alındığı Harris grafileri de incelemeye eklenmelidir. ${ }^{[2]}$

Ön-arka grafide öncelikle ayak arkası dizilimine bakılmalıdır. Düztabanlıkta artmış talokalkaneal açı ile birlikte kalkaneus valgus pozisyonundadır. Navikülanın pozisyonu talus başına göre lateral taraftadır ve talar aks 1 . metatars bazisinin mediyalinden geçer. ${ }^{[2]}$

Düztabanlıkta kalkaneus plantar fleksiyondadır ve bu durum kalkaneal inklinasyon açısı ile değerlendirilir. Normal değerleri $21-29^{\circ}$ arasında değişen bu açı, düztabanlıkta $20^{\circ}$ 'nin altına inmiştir. Talus normalden daha vertikal pozisyonda bulunur ve yan grafide talokalkaneal açı artmıştır. Mediyal arkın 
değerlendirmesinde ise mediyal longitudinal ark açısı ve Hibb açısı kullanılmaktadır. Mediyal longitudinal ark açısının normal değerleri 121,5-132,5 $5^{\circ}$ arasında değişmektedir. Düztabanlıkta açısal değer artar. Ayak mediyal longitudinal arkını yan grafi üzerinde değerlendiren diğer bir açı da Hibb açısıdır. Kalkaneus cisminin inferior korteksi boyunca çizilen çizginin birinci metatars aksı ile yaptığı açı olarak tanımlanan Hibb açısının normal değerleri $135-170^{\circ}$ arasında değişmektedir. Düztabanlıkta bu açı da artarak normal değerlerin üzerine çıkar. Yan grafide değerlendirilen bir diğer açı ise talus-1. metatars arası açıdır (Meary açısı). Bu açı mediyal longitudinal arkın çökmesi sonucu dorsal tarafa doğru yönelim gösterir. ${ }^{[12,14]}$

\section{KAYNAKLAR}

1. Vallejo JM, Jaramillo D. Normal MR imaging anatomy of the ankle and foot in the pediatric population. Magn Reson Imaging Clin N Am 2001;9(3):435-46.

2. Stein-Wexler RS, Wootton-Gorges SL, Ozonoff MB, editors. Pediatric Orthopedic Imaging. Berlin Heidelberg: SpringerVerlag; 2015. p.469.

3. Standring S, editor. Gray's Anatomy. The Anatomical Basis of Clinical Practice, Expert Consult, 40th ed. London: Churchill Livingstone; 2008.

4. Vanderwilde R, Staheli LT, Chew DE, Malagon V. Measurements on radiographs of the foot in normal infants and children. J Bone Joint Surg Am 1988;70(3):407-15.
5. Miller TT, Staron RB, Feldman F, Parisien M, Glucksman WJ, Gandolfo LH. The symptomatic accessory tarsal navicular bone: assessment with MR imaging. Radiology 1995;195(3):849-53. Crossref

6. McCarthy JJ, Drennan JC, editors. Drennan's the child's foot and ankle, 2nd ed. Philadelphia; London: Lippincott Williams \& Wilkins; 2010. Chapter 2. p.21.

7. Miller TT. Painful accessory bones of the foot. Semin Musculoskelet Radiol 2002;6(2):153-61. Crossref

8. Harty MP. Imaging of pediatric foot disorders. Radiol Clin N Am 2001;39(4):733-48.

9. Mosca VS. Flexible Flatfoot and Skewfoot. Instructional Course Lectures, The American Academy of Orthopaedic Surgeons 1995;77(12):1936-45.

10. Katz MA, Davidson RS, Chan PSH, Sullivan RJ. Plain radiographic evaluation of the pediatric foot and its deformities. U. P. O.J 1997;10:30-9.

11. Kasser JR. The Foot. In: Lovell WW, Winter RB, Morrissy RT, Weinstein SL. Lovell and Winter's Pediatric Orthopaedics, Vol II, 6th ed. Philadelphia: Lippincott Williams \& Wilkins; 2006. p.1257-329.

12. Doğan $A$, Üzümcügil $O$, Zorer $G$, Yalçınkaya M. Çocuk ayak radyografisinin değerlendirilmesi ve sık görülen konjenital ayak deformitelerinin radyografik özellikleri. Totbid Dergisi 2007;6(3-4):77-87.

13. Lateur LM, Van Hoe LR, Van Ghillewe KV, Gryspeerdt SS, Baert AL, Dereymaeker GE. Subtalar coalition: Diagnosis with the $C$ sign on lateral radiographs of the ankle. Radiology 1994;193(3):847-51. Crossref

14. Hensinger RN, editor. Foot. Standards in Pediatric Orthopedics. New York: Raven Press; 1986. p.256-81. 